\title{
THE MODE-III FRACTURE ANALYSIS OF AN INCLINED CRACK EMBEDDED IN THIN LAYER SYSTEMS BY ANALYTICAL ALTERNATING METHODS
}

\author{
Chih-Yi Chang and Chien-Ching Ma*
}

\begin{abstract}
This paper analyzes the mode-III stress intensity factor of an inclined crack, embedded in a thin layer, bonded to a half plane, subjected to arbitrary distributed anti-plane loads. Special alternating procedures are presented to evaluate the modeIII S.I.F. and the numerical results confirm the validity of the proposed alternating procedure. The solution of a bi-material problem in an infinite plane with an inclined crack and the analytical solution of a thin layer, without crack, bonded to a half plane, subjected to an anti-plane point force applied on the boundary are referred to as fundamental solutions. By using these fundamental solutions and alternating procedures, the stress intensity factors of a crack in a thin layer bonded to a half plane are evaluated. The numerical results of some reduced problems are computed and excellent agreements with existing solutions are obtained.
\end{abstract}

Key Words: alternating method, stress intensity factor, thin layer.

\section{INTRODUCTION}

The purpose of this work is to investigate the mode-III fracture analysis of an inclined crack embedded in a finite layer, bonded to a semi-infinite substrate. In the application of components of coated materials such as seals on semiconductors, it is desirable that the coated layer provide environmental protection, against corrosion and oxidation. It is important to analyze the fracture characteristic of a crack in the layer or in the substrate for the thin-layer problem. Among the published articles on the cracked thin-layer problem, Blanco et al. (1995) developed a mathematical model to deal with the general anisotropic case of a straight crack lying in the thin layer coated to a semi-infinite substrate. The crack was modeled as a continuous distribution of dislocation and the numerical results for the monoclinic case were presented in graphic form. Chao and Kao (1997)

\footnotetext{
*Corresponding author. (Tel: 886-2-23659996; Email: ccma@ntu.edu.tw)

C. Y. Chang is with the Department of Mechanical of Mechanical Engineering, Nanya Institute of Technology, Taoyuan, Taiwan 320, R.O.C.

C. C. Ma is with the Department of Mechanical Engineering, National Taiwan University, Taipei Taiwan 10617, R.O.C.
}

proposed a method that was based upon the complex potential theory and iteration of Möbius transformation that allowed them to express the solution as a rapidly convergent series. Their numerical results include the stress intensity factor, $K_{I I I}$, of a crack in a thin-layer, bonded to a half-plane and the reduced problem of a crack in a strip. Chang (1999) considered a cracked layer bonded to a viscoelastic substrate, subjected to an anti-plane point force on the boundary. The results show that the time-dependent stress intensity factor may increase or decrease with time evolution. Concerning literature on the reduced problem, Irwin (1957) obtained a theoretical solution of a normal crack in a strip subjected to crack face loadings. By a use of Fourier transform, Ma (1988) presented the theoretical solution of a modeIII central crack in a rectangular sheet, subjected to arbitrary anti-plane load on boundaries. The special case of a parallel crack in a strip was also obtained. Bassani and Erdogan (1979) considered two bonded dissimilar half planes containing an inclined crack and subjected to anti-plane crack face loads. A similar problem was considered by Wang and Meguid (1996), they applied the technique of SCI (Self-Consistent Iterative) to obtain the numerical solution and obvious difference from the theoretical solution provided 
by Bassani and Erdogan (1979). Choi and Earmme (1996) provided an alternation technique for solving sub-interface crack problems in anisotropic bimaterials, only the numerical results of the orthotropic case were computed.

Instead of analyzing the complicated crack problem with a finite boundary, the Schwartz-Neumann alternating method proposed the solution of a crack in a finite body by iteration between the solution for the noncrack body and the solution for an infinite body with a crack. Various methods used to solve the sub-problem of a noncrack body lead to various characteristics of Schwartz-Neumann alternating methods. The analytical alternating method utilized analytical solutions for the noncrack finite body, as well as for a crack in an infinite plane. Early applications of the analytical alternating method involved solving the edge crack problem in a semi-infinite plane by Hartranft and Sih (1973), and a surface crack in a 3-D body by Shah and Kobayashi (1973). The method was used later by O'Donoghue et al. (1985) to solve multiple embedded elliptical cracks in an infinite body. Zhang and Hasebe (1993) studied the interactions between rectilinear and circumferential cracks in an infinite domain. Recently, Chang and $\mathrm{Ma}$ (2001) extended the analytical alternating method to complicated geometric configurations. They studied the transient heat conduction problem of a rectangular plate with multiple insulated cracks. Chang and $\mathrm{Ma}$ (2002) analyzed the mixed-mode S.I.F. of multiple cracks in a semi-infinite plane. The finite element alternating method (FEAM) (Raju and Fichter 1989, Chen and Chang 1989, Krishnamurthy and Raju 1990) and boundary element alternating method (BEAM) (Rajiyah and Atluri 1989, Raju and Krishnamurthy 1992) extended the utilizable ability of the alternating technique to complicated cracked geometries. In the absence of cracks, FEM or BEM can easily obtain the numerical solution of the noncrack finite body with a coarser mesh.

In this study, we consider the mode-III fracture problem of cracked layer systems where the inclined crack is located at the thin layer with arbitrary angles. The alternating procedure for a bi-material problem with an inclined crack is developed first. The solution of the bi-material problem with an inclined crack and the analytical solution of a thin layer without crack bonded to a half plane subjected to an anti-plane point force applied on the boundary are referred to as fundamental solutions. By using these two fundamental solutions and proposed alternating procedures, the modeIII S.I.F. of an inclined crack in a thin layer bonded to a half plane is easily computed. The alternating procedure of an inclined crack in a strip is also presented in this paper. Numerical solutions of various cases are obtained and excellent agreement with

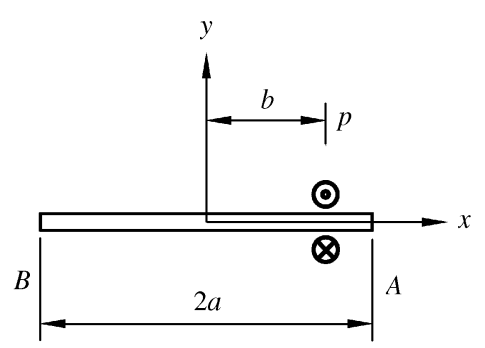

Fig. 1 A finite crack in an infinite plane subjected to a pair of anti-plane point forces

existing results are obtained. Finally, the S.I.F. of an inclined crack in a thin layer bonded to a semi-infinite plane are presented. The numerical solutions of reduced problems, in which the shear modulus of the semi-infinite plane is infinite or infinitesimal are compared to the solutions of a crack in a strip with free or fixed boundary, and excellent agreements are obtained.

\section{ANALYTICAL FUNDAMENTAL SOLUTIONS}

In the literature on Schwartz-Neumann alternating methods, various types of analytical solutions have been used to analyze different problems. Polynomial and Chebyshev polynomial distributions have been mostly employed to simulate continuously distributed loads. For discontinuously distributed loads, the point loads or piecewise distributed loads could more precisely describe the large variation of the crack face loads. For simplicity and versatility, all the analytical fundamental solutions presented in this section are point load solutions.

\section{A Finite Crack in an Infinite Plane Subjected to a Pair of Point Forces on the Crack Faces}

Figure 1 shows an infinite plane containing a finite crack lying along the $x$-axis. The center of the crack is located at the origin, and the crack length is $2 a$. The crack face is subjected to a pair of anti-plane point forces $p$ at $x=b$ and $\mu$ is the shear modulus of the material. From the well-known complex variable method, the complex stress functions are found as

$$
\begin{aligned}
& Z_{I I I}=\frac{p}{\pi} \frac{\sqrt{a^{2}-b^{2}}}{(z-b) \sqrt{z^{2}-a^{2}}} \\
& \bar{Z}_{I I I}=\frac{p}{\pi} \sin ^{-1}\left[\frac{b z-a^{2}}{a(z-b)}\right]
\end{aligned}
$$

where $z=x+i y$. The full field solutions of displacement and stresses can be expressed as

$$
W=\frac{1}{\mu} \operatorname{Im} \bar{Z}_{I I I}=\frac{p}{\mu \pi} \operatorname{Im}\left\{\sin ^{-1}\left[\frac{b z-a^{2}}{a(z-b)}\right]\right\}
$$




$$
\begin{gathered}
\tau_{x z}=\operatorname{Im} Z_{I I I}=\frac{p}{\pi} \frac{\sqrt{a^{2}-b^{2}}}{r_{3} \sqrt{r_{1} r_{2}}} \sin \left(-\frac{\phi_{1}+\phi_{2}}{2}-\phi_{3}\right) \\
\tau_{y z}=\operatorname{Re} Z_{I I I}=\frac{p}{\pi} \frac{\sqrt{a^{2}-b^{2}}}{r_{3} \sqrt{r_{1} r_{2}}} \cos \left(-\frac{\phi_{1}+\phi_{2}}{2}-\phi_{3}\right)
\end{gathered}
$$

where $r_{1}=|z-a|, r_{2}=|z+a|, r_{3}=|z-b|, \phi_{1}=\tan ^{-1}\left(\frac{y}{x-a}\right)$, $\phi_{2}=\tan ^{-1}\left(\frac{y}{x+a}\right), \phi_{3}=\tan ^{-1}\left(\frac{y}{x-b}\right)$ and the stress intensity factors of crack tips $\mathrm{A}$ and $\mathrm{B}$ are

$$
\begin{aligned}
& K_{\text {IIIA }}=\frac{p}{\sqrt{\pi a}} \sqrt{\frac{a+b}{a-b}} \\
& K_{\text {IIIB }}=\frac{p}{\sqrt{\pi a}} \sqrt{\frac{a-b}{a+b}}
\end{aligned}
$$

\section{The Bi-material Problem Subjected to an Anti- plane Point Force}

Figure 2 shows a bi-material problem subjected to an anti-plane point force with magnitude $p$ at ( $\xi$, $h)$ and $\mu_{1}$ and $\mu_{2}$ are the shear moduli of material 1 and 2 , respectively. The governing equations could be expressed as

$$
\begin{array}{ll}
\frac{\partial^{2} W_{1 A}}{\partial x^{2}}+\frac{\partial^{2} W_{1 A}}{\partial y^{2}}=0 & y \geq h \\
\frac{\partial^{2} W_{1 B}}{\partial x^{2}}+\frac{\partial^{2} W_{1 B}}{\partial y^{2}}=0 & 0 \leq y<h \\
\frac{\partial^{2} W_{2}}{\partial x^{2}}+\frac{\partial^{2} W_{2}}{\partial y^{2}}=0 & y<0
\end{array}
$$

The continuity conditions are

$$
\begin{aligned}
& W_{1 A}(x, h)=W_{1 B}(x, h) \\
& W_{1 B}(x, 0)=W_{2}(x, 0) \\
& \frac{\partial W_{1 B}(x, 0)}{\partial y}=\frac{\partial W_{2}(x, 0)}{\partial y}
\end{aligned}
$$

and the jumped condition is

$$
\frac{p \delta(x-\xi)}{\mu_{1}}+\frac{\partial W_{1 A}(x, h)}{\partial y}=\frac{\partial W_{1 B}(x, h)}{\partial y}
$$

The Fourier transformation pair is

$$
\begin{aligned}
& F(\omega)=\int_{-\infty}^{\infty} f(x) e^{-i \omega x} d x \\
& f(x)=\frac{1}{2 \pi} \int_{-\infty}^{\infty} F(\omega) e^{i \omega x} d \omega
\end{aligned}
$$

The solutions of displacement field in the Fourier transform domain are

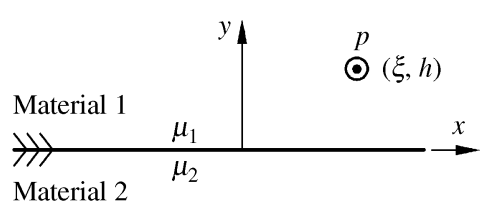

Fig. 2 The bi-material problem subjected to an anti-plane point force

$$
\bar{W}_{1 A}=\frac{p}{|\omega|}\left[\frac{1}{2 \mu_{1}} e^{|\omega|(h-y)}+\frac{\mu_{1}-\mu_{2}}{2 \mu_{1}\left(\mu_{1}+\mu_{2}\right)} e^{-|\omega|(h+y)}\right]
$$

$$
\begin{aligned}
& \bar{W}_{1 B}=\frac{p}{|\omega|}\left[\frac{1}{2 \mu_{1}} e^{-|\omega|(h-y)}+\frac{\mu_{1}-\mu_{2}}{2 \mu_{1}\left(\mu_{1}+\mu_{2}\right)} e^{-|\omega|(h+y)}\right] \\
& \bar{W}_{2}=\frac{p}{|\omega|} \frac{1}{\left(\mu_{1}+\mu_{2}\right)} e^{-|\omega|(h-y)}
\end{aligned}
$$

After the inverse transformation procedure, the stress field of materials 1 and 2 could be expressed as

$$
\begin{aligned}
\tau_{x z 1}= & -\frac{p}{2 \pi} \frac{x-\xi}{(x-\xi)^{2}+(y-h)^{2}} \\
& -\frac{p}{2 \pi} \frac{\left(\mu_{1}-\mu_{2}\right)}{\left(\mu_{1}+\mu_{2}\right)} \frac{x-\xi}{(x-\xi)^{2}+(y+h)^{2}} \\
\tau_{y z 1}= & -\frac{p}{2 \pi} \frac{y-h}{(x-\xi)^{2}+(y-h)^{2}} \\
& -\frac{p}{2 \pi} \frac{\mu_{1}-\mu_{2}}{\left(\mu_{1}+\mu_{2}\right)} \frac{y+h}{(x-\xi)^{2}+(y+h)^{2}} \\
\tau_{x z 2}= & -\frac{p}{2 \pi} \frac{2 \mu_{2}}{\left(\mu_{1}+\mu_{2}\right)} \frac{x-\xi}{(x-\xi)^{2}+(y-h)^{2}} \\
\tau_{y z 2}= & -\frac{p}{2 \pi} \frac{2 \mu_{2}}{\left(\mu_{1}+\mu_{2}\right)} \frac{y-h}{(x-\xi)^{2}+(y-h)^{2}}
\end{aligned}
$$

From the solution presented in Eq. (10), the solution of a bi-material problem subjected to an anti-plane point force can be represented a simple form as

$$
S\left(z, z_{0}\right)= \begin{cases}\boldsymbol{S}_{0}\left(z, z_{0}\right)+\frac{\mu_{1}-\mu_{2}}{\mu_{1}+\mu_{2}} S_{0}\left(z, z_{0}^{\prime}\right), & y \geq 0 \\ \frac{2 \mu_{2}}{\mu_{1}+\mu_{2}} S_{0}\left(z, z_{0}\right), & y<0\end{cases}
$$

where $S_{0}\left(z, z_{0}\right)$ denotes the solution of an infinite plane subjected to an anti-plane force $p$ at $z_{0}(\xi, h)$ and $S_{0}\left(z, z_{0}^{\prime}\right)$ denotes the solution of an infinite plane subjected to an anti-plane force $p$ at $z_{0}^{\prime}(\xi,-h)$. The physical representation of this fundamental solution is shown in Fig. 3. 


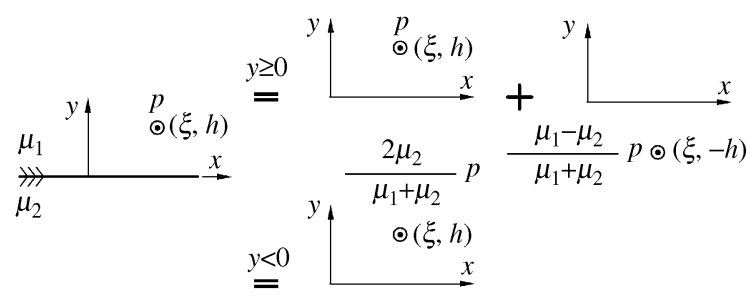

Fig. 3 The physical representation of the solution of bi-material problem subjected to an anti-plane point force

\section{A Thin Layer Bonded to a Half Plane Subjected to a Point Force on the Boundary}

Figure 4 shows a layer with finite thickness bonded to a half plane subjected to a point force on the boundary. The origin of the coordinate is located at the interface and the thickness of the layer is $h$. An anti-plane concentrated force with magnitude $p$ is applied on the boundary at $x=\xi$. The governing equations are

$$
\begin{array}{ll}
\frac{\partial^{2} W_{1}}{\partial x^{2}}+\frac{\partial^{2} W_{1}}{\partial y^{2}}=0 & 0 \leq y<h \\
\frac{\partial^{2} W_{2}}{\partial x^{2}}+\frac{\partial^{2} W_{2}}{\partial y^{2}}=0 & y<0
\end{array}
$$

The boundary conditions and continuity equations are

$$
\begin{array}{ll}
\mu_{1} \frac{\partial W_{1}}{\partial y}=p \delta(x-\xi), & y=h \\
W_{1}=W_{2}, & y=0 \\
\mu_{1} \frac{\partial W_{1}}{\partial y}=\mu_{2} \frac{\partial W_{2}}{\partial y}, & y=0
\end{array}
$$

The solutions of displacement in the transform domain are

$$
\begin{aligned}
& \bar{W}_{1}=\frac{p}{\mu_{1}|\omega|} \\
& \cdot \sum_{n=0}^{\infty}\left\{K^{n+1} e^{-|\omega|[(2 n+1) h+y]}+K^{n} e^{-|\omega|[(2 n+1) h-y]}\right\} \\
& \bar{W}_{2}=\frac{2}{\left(\mu_{1}+\mu_{2}\right)} \frac{p}{|\omega|} \sum_{n=0}^{\infty} K^{n} e^{-|\omega|[(2 n+1) h-y]}
\end{aligned}
$$

where $K=\frac{\mu_{1}-\mu_{2}}{\mu_{1}+\mu_{2}}$. The solutions of stress field are expressed in series forms as

$$
\tau_{x z 1}=\frac{-p}{\pi} \sum_{n=0}^{\infty}\left[\begin{array}{c}
K^{n+1} \frac{x-\xi}{(x-\xi)^{2}+[(2 n+1) h+y]^{2}} \\
+K^{n} \frac{x-\xi}{(x-\xi)^{2}+[(2 n+1) h-y]^{2}}
\end{array}\right]
$$

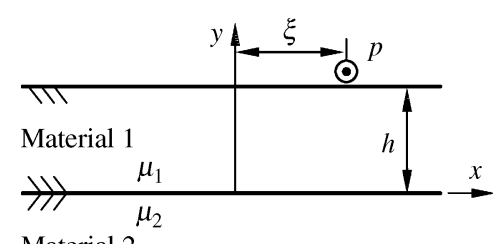

Material 2

Fig. 4 A thin layer bonded to a half plane subjected to a point force on the boundary

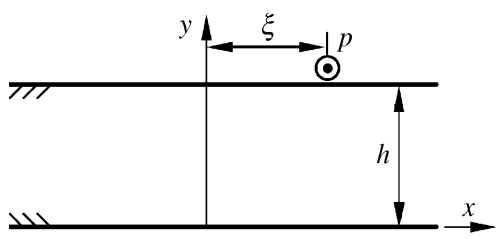

Fig. 5 A strip subjected to a point force applied on the upper boundary

$$
\tau_{y z 1}=\frac{p}{\pi} \sum_{n=0}^{\infty}\left[\begin{array}{c}
-K^{n+1} \frac{(2 n+1) h+y}{(x-\xi)^{2}+[(2 n+1) h+y]^{2}} \\
+K^{n} \frac{(2 n+1) h-y}{(x-\xi)^{2}+[(2 n+1) h-y]^{2}}
\end{array}\right]
$$

$$
\begin{gathered}
\tau_{x z 2}=\frac{2 \mu_{2}}{\mu_{1}+\mu_{2}} \frac{-p}{\pi} \sum_{n=0}^{\infty}\left[K^{n} \frac{x-\xi}{(x-\xi)^{2}+[(2 n+1) h-y]^{2}}\right] \\
\tau_{y z 2}=\frac{2 \mu_{2}}{\mu_{1}+\mu_{2}}-\frac{p}{\pi} \sum_{n=0}^{\infty}\left[K^{n} \frac{(15 c)}{(x-\xi)^{2}+[(2 n+1) h-y]^{2}}\right]
\end{gathered}
$$

\section{A Strip Subjected to a Point Force on the Bound- ary}

Figure 5 shows a strip subjected to a point force $p$ on the upper boundary at $x=\xi$. The governing equation is

$$
\frac{\partial^{2} W}{\partial x^{2}}+\frac{\partial^{2} W}{\partial y^{2}}=0
$$

and the boundary conditions are

$$
\begin{array}{ll}
\mu \frac{\partial W}{\partial y}=0, & y=0 \\
\mu \frac{\partial W}{\partial y}=p \delta(x-\xi), & y=h
\end{array}
$$

The displacement and stress in the transform domain are

$$
\bar{W}=\frac{p}{\mu \omega} \frac{\cosh \omega y}{\sinh \omega h}
$$




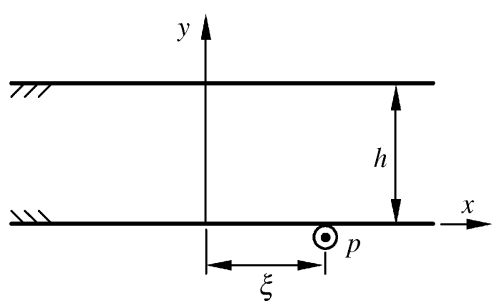

Fig. 6 A strip subjected to a point force applied on the lower boundary

$$
\begin{aligned}
& \bar{\tau}_{x z}=i p \frac{\cosh \omega y}{\sinh \omega h} \\
& \bar{\tau}_{y z}=p \frac{\sinh \omega y}{\sinh \omega h}
\end{aligned}
$$

The stress field solutions can be represented with explicit functional forms as

$$
\begin{gathered}
\tau_{x z}=\frac{p}{2 h} \frac{-\sinh \frac{\pi(x-\xi)}{h}}{\cos \frac{\pi y}{h}+\cosh \frac{\pi(x-\xi)}{h}} \\
\tau_{y z}=\frac{p}{2 h} \frac{\sin \frac{\pi y}{h}}{\cos \frac{\pi y}{h}+\cosh \frac{\pi(x-\xi)}{h}}
\end{gathered}
$$

Similarly, the solutions of stresses in a strip subjected to a point force $p$ on the lower boundary at $x=\xi$ as shown in Fig. 6 are

$$
\begin{gathered}
\tau_{y z}=\frac{p}{2 h} \frac{\sin \frac{\pi(y-h)}{h}}{\cos \frac{\pi(y-h)}{h}+\cosh \frac{\pi(x-\xi)}{h}} \\
\tau_{x z}=\frac{p}{2 h} \frac{-\sinh \frac{\pi(x-\xi)}{h}}{\cos \frac{\pi(y-h)}{h}+\cosh \frac{\pi(x-\xi)}{h}}
\end{gathered}
$$

\section{A Strip with a Concentrated Load Applied at the Upper Boundary and Lower Boundary is Fixed}

Figure 7 shows the geometrical configuration of the problem. The boundary conditions are

$$
\begin{array}{ll}
W=0, & y=0 \\
\mu \frac{\partial W}{\partial x}=p \delta(x-\xi), & y=h
\end{array}
$$

The displacement and stress in the transform form are

$$
\begin{aligned}
& \bar{W}=\frac{p}{\mu \omega} \frac{\sinh \omega y}{\cosh \omega h} \\
& \bar{\tau}_{x z}=i p \frac{\sinh \omega y}{\cosh \omega h} \\
& \bar{\tau}_{y z}=p \frac{\cosh \omega y}{\cosh \omega h}
\end{aligned}
$$

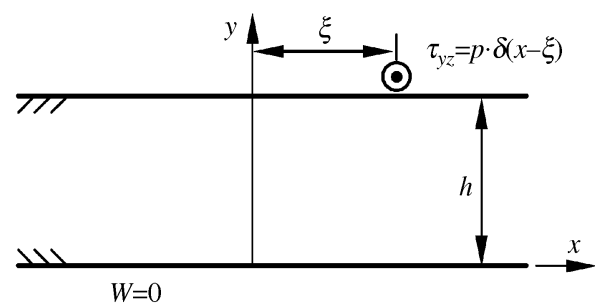

Fig. 7 A strip with fixed lower boundary subjected to a point force on the upper boundary

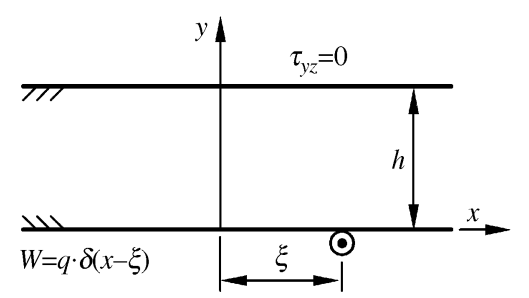

Fig. 8 A strip traction free on the upper boundary subjected to a point displacement on the lower boundary

The stress field solutions are

$$
\begin{aligned}
\tau_{x z}= & \frac{p}{4 h}\left[\frac{\sinh \frac{\pi(x-\xi)}{2 h}}{\cosh \frac{\pi(x-\xi)}{2 h}+\sin \frac{\pi y}{2 h}}\right. \\
& -\frac{\sinh \frac{\pi(x-\xi)}{2 h}}{\left.\cosh \frac{\pi(x-\xi)}{2 h}-\sin \frac{\pi y}{2 h}\right]} \\
\tau_{y z}= & \frac{2 p}{h} \frac{\cos \frac{\pi y}{2 h} \cdot \cosh \frac{\pi(x-\xi)}{2 h}}{\cosh \frac{\pi(x-\xi)}{h}+\cos \frac{\pi y}{h}}
\end{aligned}
$$

Fig. 8 shows a strip traction free on the upper boundary and subjected to a point displacement $W=q \cdot \delta(x-\xi)$ applied on the lower boundary. The stress fields are

$$
\begin{aligned}
\tau_{x z}= & \frac{\mu \pi q}{h^{2}}\left[\frac{\sinh \frac{\pi(x-\xi)}{2 h} \sin \frac{\pi y}{2 h}}{2\left(\cosh \frac{\pi(x-\xi)}{h}-\cos \frac{\pi y}{h}\right)}\right. \\
- & \left.\frac{\cosh \frac{\pi(x-\xi)}{2 h} \sinh \frac{\pi(x-\xi)}{h} \sin \frac{\pi y}{2 h}}{\left(\cosh \frac{\pi(x-\xi)}{h}-\cos \frac{\pi y}{h}\right)^{2}}\right]
\end{aligned}
$$

$$
\begin{aligned}
\tau_{y z}= & \frac{\mu q}{h^{2}}\left[\frac{\cosh \frac{\pi(x-\xi)}{2 h} \cos \frac{\pi y}{2 h}}{2\left(\cosh \frac{\pi(x-\xi)}{h}-\cos \frac{\pi y}{h}\right)}\right. \\
- & \left.\frac{\cosh \frac{\pi(x-\xi)}{2 h} \sin \frac{\pi y}{2 h} \sin \frac{\pi y}{h}}{\left(\cosh \frac{\pi(x-\xi)}{h}-\cos \frac{\pi y}{h}\right)^{2}}\right]
\end{aligned}
$$




\section{ALTERNATING PROCEDURE FOR AN INCLINED CRACK IN A THIN LAYER BONDED TO A HALF PLANE}

In this section, analytical alternating procedures will be proposed to analyze the S.I.F. of an inclined crack in a thin layer bonded to a half plane. In order to illustrate the alternating procedure, a fracture problem is considered as shown in Fig. 9(a) in which an arbitrarily distributed loading is applied on the boundary of the thin layer with an embedded inclined crack bonded to a half plane. The iteration and superposition are performed with external and internal alternating procedures.

\section{External Alternating Procedure}

(i) Solve the non-crack problem of a thin layer bonded to a half plane under distributed loads $T_{b}^{(0)}$ as shown in Fig. 9(b) by integration of the solution given in Eq. (15). Evaluate the stress distribution $f_{c}^{(1)}$ in the non-crack body at the crack surfaces of the fictitious cracks. To satisfy the traction free condition on the crack faces, the sub-problem of Fig. 9(c) that is subjected to residual stress $f_{c}^{(1)}$ at the crack faces, should be superposed.

(ii) The sub-problem Fig. 9(c) could be further split into two sub-problems as indicated in Fig. 9(d) and Fig. 9(e). Fig. 9(d) shows a crack in a bimaterial, subjected to the same traction $f_{c}^{(1)}$ on the crack faces as shown in Fig. 9(c). Evaluate the residual stress $T_{b}^{(1)}$ on the virtual boundary by the internal alternating procedure that will be described later. The problem indicated in Fig. 9 (e) is similar to that shown in Fig. 9(a), and the procedure will be iterated.

(iii) After several cycles of iteration, the residual traction $f_{c}^{(k)}$ on the crack faces of the $k^{\prime}$ th cycle of iteration will be very small; then the solution of Fig. 9(a) may be obtained by the superposition of Fig. 9(b) and Fig. 9(d) for $k$ times. The S.I.F. of the embedded crack for the original problem as shown in Fig. 9(a) can be evaluated by considering the bi-material problem with a crack subjected to the crack face loads

$$
f_{c}=\sum_{i=1}^{k} f_{c}^{(i)}
$$

(iv) The convergence criterion for the iteration in this paper is taken as

$$
\frac{\int f_{c}^{(k+1)}\left(\xi_{c}\right) d \xi_{c}-\int f_{c}^{(k)}\left(\xi_{c}\right) d \xi_{c}}{\int f_{c}^{(k)}\left(\xi_{c}\right) d \xi_{c}}<10^{-5}
$$

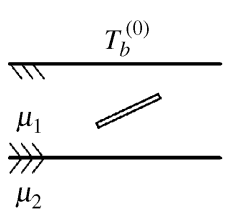

(a)

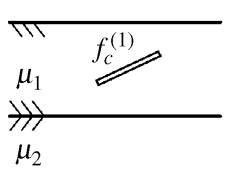

(c)

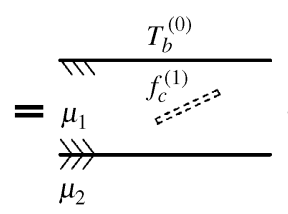

(b)

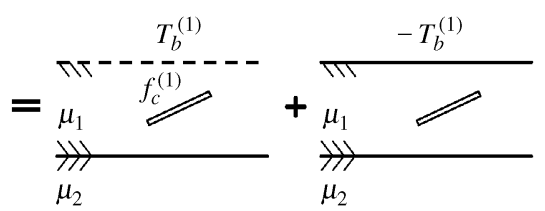

(d)

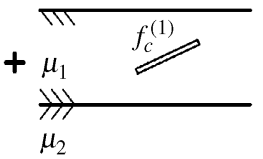

(c)

(e)
Fig. 9 The external alternating procedure of a crack in a thin layer bonded to a half plane

\section{Internal Alternating Procedure}

In the abovementioned external iteration procedure, the solution of a bi-material problem with a crack as shown in Fig. 9(d) can be constructed by the procedure indicated in Fig. 10, in which $f_{c}^{(k)}$ in Fig. 10(a) is the surface traction of the crack face in the $k^{\prime}$ th external alternating procedure. This alternating procedure is based on the solution of a bi-material problem subjected to an anti-plane force and the validity will be verified by numerical results. The solution of Fig. 10(a) may be obtained by the following internal alternating procedures.

(i) Consider a bi-material problem with a crack subjected to the traction $f_{c}^{(k)}$ on crack faces as shown in Fig. 10(a). The stress field for $y \geq 0$ can be split into two sub-problems as indicated in Fig. 10(b) and Fig. 10(c), that is an infinite plane with a crack. Evaluate the traction $g_{c}^{(1)}$ on the fictitious crack of the sub-problem of Fig. 10(c) under crack surface loads $\frac{\mu_{1}-\mu_{2}}{\mu_{1}+\mu_{2}} f_{c}^{(k)}$ on the image crack. The problem indicated in Fig. 10(d) is similar to that shown in Fig. 10(a), and the procedure will be iterated.

(ii) After several cycles of iteration, the residual stress $g_{c}^{(j)}$ approaches zero, the solution of Fig. 10(a) can be obtained by combining the solutions for the infinite plate with a single crack subjected to the crack face loads $g_{c}$ as

$$
g_{c}=f_{c}^{(k)}+\sum_{j=1}^{\infty} g_{c}^{(j)}
$$

(iii) The convergence criterion of this iteration is taken as

$$
\frac{\int g_{c}^{(j+1)}\left(\xi_{c}\right) d \xi_{c}-\int g_{c}^{(j)}\left(\xi_{c}\right) d \xi_{c}}{\int g_{c}^{(j)}\left(\xi_{c}\right) d \xi_{c}}<10^{-5}
$$




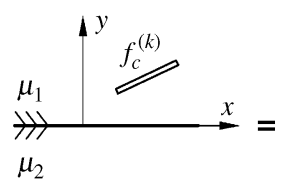

(a)

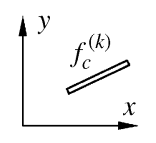

(b)

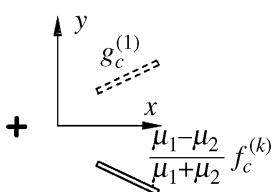

(c)

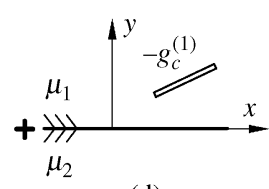

(d)
Fig. 10 The internal alternating procedure of a crack in a bi-material

\section{ALTERNATING PROCEDURE FOR A CRACK IN A STRIP}

Consider an inclined crack in a strip subjected to a traction $T_{b}^{(0)}$ on upper boundary with the lower boundary fixed. The alternating procedure could be illustrated by Fig. 11 in which the original problem is shown in Fig. 11(a).

(i) Solve the non-crack problem of a strip under given loads $T_{b}^{(0)}$ as shown in Fig. 11(b) by integration of the solution given in Eq. (23). Evaluate the stress distribution $f_{c}^{(1)}$ in the non-crack body at the crack surfaces of the fictitious cracks. To satisfy the traction free condition on the crack faces, the sub-problem of Fig. 11(c) that is subjected to residual stress $f_{c}^{(1)}$ at the crack faces should be superposed.

(ii) The sub-problem Fig. 11(c) may be further split into two sub-problems as indicated in Fig. 11(d) and Fig. 11(e). Fig. 11(d) shows a crack in an infinite plane, subjected to the same traction $f_{c}^{(1)}$ on the crack faces as shown in Fig. 11(c). Evaluate the residual stress $T_{b}^{(1)}$ and residual displacement $W_{b}^{(1)}$ on the virtual boundary as the original strip. The problem indicated in Fig. 11(e) is similar to that shown in Fig. 11(a), and the procedure will be iterated.

\section{NUMERICAL RESULTS AND DISCUSSIONS}

To examine the validity of the proposed analytical alternating method, several configurations of cracked bodies and loading conditions are analyzed. First, the results of an inclined crack in a bi-material are checked with the existing solutions. The accuracy proves the applicability of the alternating procedure of bi-material problem with a crack. Next, an inclined crack in a strip with various loads and boundary conditions is considered and excellent agreements are found when compared with the results obtained from the literature. Finally, the solutions of an

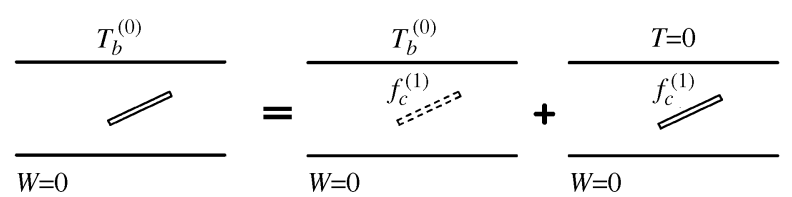

(a)

(b)

(c)

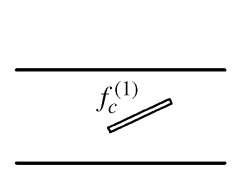

(c)

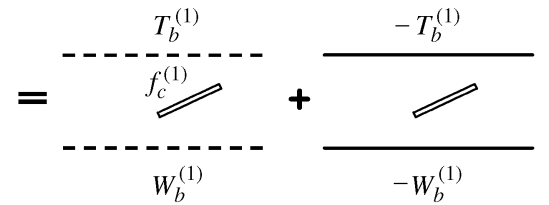

(d)

(e)
Fig. 11 Alternating procedure for a crack in a strip

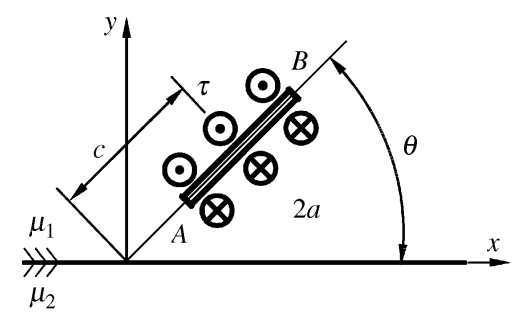

Fig. 12 An inclined crack in a bi-material subjected to uniform anti-plane shear loads $\tau$ at crack faces

inclined crack in a thin layer bonded to a half plane are compared with the existing results. The reduced problems show that the shear moduli of the half plane are infinite or infinitesimal and are checked with the solutions of a crack in a strip with free or fixed lower boundary, and the excellent agreements prove the validity of the present method.

\section{An Inclined Crack in a Bi-material}

Consider an inclined crack near the interface of bonded half planes subjected to uniformly distributed anti-plane shear loads $\tau$ on crack faces as shown in Fig. 12, the inclined angle is $\theta$ and the distance between the crack center and the interface is $c$. The normalized stress intensity factors of crack tips $A$ and $B$ are given as

$$
F_{I I I}=K_{I I I} \cdot \frac{1}{\tau \sqrt{\pi a}}
$$

The numerical results for different values of $c / a$ and inclined angle $\theta$ are compared with those obtained by Bassani and Erdogan (1979). Excellent agreements are found as indicated in Tables 1 3, the only distinct value being symbolized by $(*)$. The critical case $\mu_{2}=0$ denotes the problem of an inclined crack in a semi-infinite plane with traction free condition. The numerical accuracy proves the practicability of the alternating procedure for a crack in a bi-material. 
Table 1 Comparisons of normalized mode-III S.I.F. $\left(F_{I I I}\right)$ for an inclined crack in a bi-material $\left(\mu_{1} / \mu_{2}=\right.$ 0.0433)

\begin{tabular}{|c|c|c|c|c|c|c|c|c|c|c|c|c|}
\hline \multicolumn{5}{|c|}{$\mu_{1} / \mu_{2}=0.0433, \theta=\pi / 8$} & \multicolumn{4}{|c|}{$\theta=\pi / 4$} & \multicolumn{4}{|c|}{$\theta=\pi / 2$} \\
\hline & $F_{I I}$ & & $F_{I I}$ & & $F_{I I}$ & & $F_{I I}$ & & $F_{I I I}$ & & $F_{I}$ & \\
\hline$c / a$ & $\begin{array}{c}\text { Bassani \& } \\
\text { Erdogan } \\
(1979)\end{array}$ & & $\begin{array}{c}\text { Bassani \& } \\
\text { Erdogan } \\
(1979)\end{array}$ & & $\begin{array}{c}\text { Bassani \& } \\
\text { t Erdogan } \\
(1979)\end{array}$ & & $\begin{array}{c}\text { Bassani \& } \\
\text { Erdogan } \\
(1979)\end{array}$ & & $\begin{array}{c}\text { Bassani \& } \\
\text { Erdogan } \\
(1979)\end{array}$ & & $\begin{array}{c}\text { Bassani \& } \\
\text { Erdogan } \\
(1979)\end{array}$ & \\
\hline 1.0 & 0.659 & $0.660^{*}$ & 0.852 & & 0.622 & & 0893 & & 0.610 & & 0.916 & \\
\hline 1. & 6 & 0 & & & & & 00 & & 2 & & & \\
\hline 1.1 & .719 & 7 & 0 . & & & & 06 & & 0 & ) & 31 & 31 \\
\hline 1.2 & .75 & 7 & & & & & 16 & & 7 & & 41 & 41 \\
\hline 1.5 & 04 & 0.804 & & & & & & & & & 59 & 59 \\
\hline 2.0 & 865 & 0.865 & & & & & & & 9 & 9 & 76 & 76 \\
\hline 5 & 970 & 0.970 & & & & & & & 5 & & & 6 \\
\hline 10 & & 0.992 & & & & & & & & & & 99 \\
\hline$\infty$ & 1.000 & 1.000 & 1.000 & 1.000 & 1.000 & 1.000 & 1.000 & 1.000 & 1.000 & 1.000 & 1.000 & 1.000 \\
\hline
\end{tabular}

Table 2 Comparisons of normalized mode-III S.I.F. $\left(F_{I I I}\right)$ for an inclined crack in a bi-material $\left(\mu_{1} / \mu_{2}=\right.$ 23.08)

\begin{tabular}{|c|c|c|c|c|c|c|c|c|c|c|c|c|}
\hline \multicolumn{5}{|c|}{$\mu_{1} / \mu_{2}=23.08, \theta=\pi / 8$} & \multicolumn{4}{|c|}{$\theta=\pi / 4$} & \multicolumn{4}{|c|}{$\theta=\pi / 2$} \\
\hline & \multicolumn{2}{|c|}{$F_{\text {IIIA }}$} & \multicolumn{2}{|c|}{$F_{I I I B}$} & \multicolumn{2}{|c|}{$F_{\text {IIIA }}$} & \multicolumn{2}{|c|}{$F_{I I I B}$} & \multicolumn{2}{|c|}{$F I_{I I I A}$} & \multicolumn{2}{|c|}{$F_{I I I B}$} \\
\hline$c / a$ & $\begin{array}{c}\text { Bassani \& } \\
\text { Erdogan } \\
(1979)\end{array}$ & Present & $\begin{array}{c}\text { Bassani \& } \\
\text { Erdogan } \\
(1979)\end{array}$ & Present & $\begin{array}{c}\text { Bassani \& } \\
\text { Erdogan } \\
(1979)\end{array}$ & Present & $\begin{array}{c}\text { Bassani \& } \\
\text { Erdogan } \\
(1979)\end{array}$ & Present & $\begin{array}{c}\text { Bassani \& } \\
\text { Erdogan } \\
(1979)\end{array}$ & Present & $\begin{array}{c}\text { Bassani \& } \\
\text { Erdogan } \\
(1979)\end{array}$ & Present \\
\hline 1.05 & 222 & $2.21 *$ & 1.34 & 1.34 & 187 & 18 & 119 & 1 & 1.70 & 1.7 & 1.13 & 1.13 \\
\hline 1.10 & 1.87 & & 1. & & & 1.5 & 1.16 & & 1.44 & 1. & 1.11 & \\
\hline 1.15 & 1.71 & 1.71 & 1.28 & 1.28 & 1.44 & 1.44 & 1.14 & 1.1 & 1.32 & 1.32 & 1.09 & 1.09 \\
\hline 1.25 & 1.53 & 1.53 & 1.24 & 1.24 & 1.30 & 1.31 & 1.12 & 1.12 & 1.21 & 1.21 & 1.07 & 1.07 \\
\hline 1.50 & 1.33 & 1.33 & 1.18 & 1.18 & 1.17 & 1.17 & 1.08 & 1.08 & 1.10 & 1.10 & 1.05 & 1.05 \\
\hline 2.00 & 1.18 & 1.18 & 1.12 & 1.12 & 1.08 & 1.08 & 1.05 & 1.05 & 1.04 & 1.04 & 1.03 & 1.03 \\
\hline 5.00 & 1.03 & 1.03 & 1.03 & 1.03 & 1.01 & 1.01 & 1.01 & 1.01 & 1.00 & 1.00 & 1.00 & 1.00 \\
\hline 10.0 & 1.01 & 1.01 & 1.01 & 1.01 & 1.00 & 1.00 & 1.00 & 1.00 & 1.00 & 1.00 & 1.00 & 1.00 \\
\hline$\infty$ & 1.00 & 1.00 & 1.00 & 1.00 & 1.00 & 1.00 & 1.00 & 1.00 & 1.00 & 1.00 & 1.00 & 1.00 \\
\hline
\end{tabular}

\section{An Inclined Crack in a Strip}

\section{(i) Uniform Anti-Plane Shear Stress Loads Applied} at Boundaries for $-d<x<d$

Figure 13 shows a parallel crack in a strip subjected to an anti-plane uniformly distributed shear stress at boundaries for $-d<x<d$ Table 4 shows the dimensionless mode-III S.I.F. for different values of $a / h$. Excellent agreements are obtained if compared with the solutions of Ma (1988) who also analyzed the same problem.

\section{(ii) Two Pairs of Anti-Plane Point Forces Applied at Boundaries}

Consider a parallel crack in a strip subjected to two pairs of anti-plane point forces applied at boundaries as shown in Fig. 14. Table 5 shows the dimensionless mode-III S.I.F. for different values of $a / h$. Again, excellent agreements with the solutions of Ma (1988) are obtained.

(iii) A Pair of Anti-Plane Point Forces Applied at Boundaries

Consider an inclined crack in a strip subjected to a pair of anti-plane point forces $2 p$ applied at boundaries as shown in Fig. 15. The inclined angle is $\theta$. Table 6 shows the dimensionless mode-III S.I.F. for different values of $a / h$ and $\theta$. There are obvious differences between the present results and Chao and Kao (1997). However, for the special case of $a / h=0.5$ and $\theta=0^{\circ}$, the present result is the same as Ma (1988) 
Table 3 Comparisons of normalized mode-III S.I.F. $\left(F_{I I I}\right)$ for an inclined crack in a bi-material $\left(\mu_{2}=0\right)$

\begin{tabular}{|c|c|c|c|c|c|c|c|c|c|c|c|c|}
\hline \multicolumn{5}{|c|}{$\mu_{2}=0, \theta=\pi / 8$} & \multicolumn{4}{|c|}{$\theta=\pi / 4$} & \multicolumn{4}{|c|}{$\theta=\pi / 2$} \\
\hline & \multicolumn{2}{|c|}{$F_{I I I A}$} & \multicolumn{2}{|c|}{$F_{I I I B}$} & \multicolumn{2}{|c|}{$F_{I I I A}$} & \multicolumn{2}{|c|}{$F_{I I I B}$} & \multicolumn{2}{|c|}{$F I_{I I I A}$} & \multicolumn{2}{|c|}{$F_{I I I B}$} \\
\hline$c / a$ & $\begin{array}{c}\text { Bassani \& } \\
\text { Erdogan } \\
(1979)\end{array}$ & Present & $\begin{array}{c}\text { Bassani \& } \\
\text { Erdogan } \\
(1979)\end{array}$ & Present & $\begin{array}{c}\text { Bassani \& } \\
\text { Erdogan } \\
(1979)\end{array}$ & Present & $\begin{array}{c}\text { Bassani \& } \\
\text { Erdogan } \\
(1979)\end{array}$ & Present & $\begin{array}{c}\text { Bassani \& } \\
\text { Erdogan } \\
(1979)\end{array}$ & Present & $\begin{array}{c}\text { Bassani \& } \\
\text { Erdogan } \\
(1979)\end{array}$ & Present \\
\hline 1.05 & 2.48 & 2.48 & 1.40 & 1.40 & 2.01 & 2.0 & 1.22 & 1.22 & 1.79 & 1.79 & 1.15 & 1.15 \\
\hline 1.10 & 2.03 & 2.03 & 1.35 & 1.35 & 1.66 & 1.66 & 1.18 & 1.1 & 1.49 & 1.49 & 1.12 & 1.12 \\
\hline 1.15 & 1.82 & 1.82 & 1.32 & 1.32 & 1.50 & 1.50 & 1.16 & 1.1 & 1.36 & 1.36 & 1.10 & 1.10 \\
\hline 1.25 & 1.60 & 1.60 & 1.27 & 1.27 & 1.34 & 1.34 & 1.13 & 1.1 & 1.23 & 1.23 & 1.08 & 1.08 \\
\hline 1.50 & 1.37 & 1.37 & 1.20 & 1.20 & 1.18 & 1.18 & 1.09 & 1.09 & 1.11 & 1.11 & 1.05 & 1.05 \\
\hline 2.00 & 1.20 & 1.2 & 1.13 & 1.13 & 1.09 & 1.09 & 1.05 & 1.0 & 1.05 & 1.05 & 1.03 & 1.03 \\
\hline 5.00 & 1.04 & 1.04 & 1.03 & 1.03 & 1.01 & 1.01 & 1.01 & 1.01 & 1.01 & 1.01 & 1.00 & 1.00 \\
\hline 10.0 & 1.01 & 1.0 & 1.01 & 1.0 & 1.00 & 1.00 & 1.00 & 1.00 & 1.00 & 1.00 & 1.00 & 1.00 \\
\hline$\infty$ & 1.00 & 1.00 & 1.00 & 1.00 & 1.00 & 1.00 & 1.00 & 1.00 & 1.00 & 1.00 & 1.00 & 1.00 \\
\hline
\end{tabular}

Table 4 Dimensionless mode-III S.I.F. of a parallel crack in a strip subjected to an antiplane uniformly distributed shear stress at boundaries for $-\boldsymbol{d}<\boldsymbol{x}<\boldsymbol{d}$

\begin{tabular}{cccccc}
\hline \multirow{2}{*}{$a / h$} & \multicolumn{2}{c}{$K_{I I I} / \tau \sqrt{a}(d=a)$} & & \multicolumn{2}{c}{$K_{I I I} / \tau \sqrt{a}(d=\infty)$} \\
\cline { 2 - 3 } \cline { 5 - 6 } & Present & Ma (1988) & & Present & Ma $(1988)$ \\
\hline 4 & 1.548 & 1.548 & & 1.772 & 1.772 \\
2 & 1.061 & 1.061 & & 1.377 & 1.377 \\
1 & 0.702 & 0.702 & & 1.149 & 1.149 \\
0.5 & 0.431 & 0.431 & & 1.047 & 1.047 \\
0.25 & 0.239 & 0.239 & & 1.013 & 1.013 \\
\hline
\end{tabular}

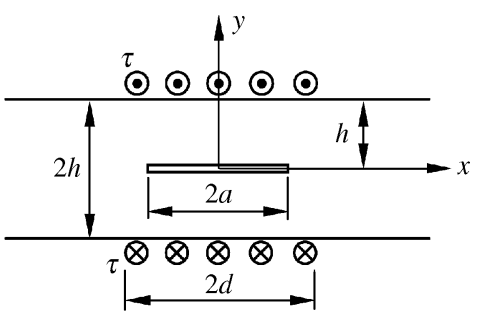

Fig. 13 A parallel crack in a strip subjected to an anti-plane uniformly distributed shear stress $\tau$ at boundaries for $-d<x<d$

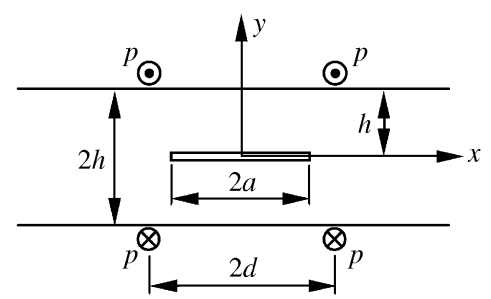

Fig. 14 A parallel crack in a strip subjected to two pairs of antiplane point forces applied at boundaries

(iv) Uniform Anti-Plane Shear Stress Applied at Crack Faces

Consider an inclined crack in a strip subjected
Table 5 Dimensionless mode-III S.I.F. of a parallel crack in a strip subjected to two pairs of anti-plane point forces applied at boundaries

\begin{tabular}{cccccc}
\hline \multirow{2}{*}{$a / h$} & \multicolumn{2}{c}{$K_{I I I} \sqrt{a} / p(d=0)$} & & \multicolumn{2}{c}{$K_{I I I} \sqrt{a} / p(d=a)$} \\
\cline { 2 - 3 } \cline { 5 - 6 } & Present & Ma (1988) & & Present & Ma (1988) \\
\hline 4 & 1.596 & 1.596 & & 1.128 & 1.128 \\
2 & 1.126 & 1.126 & & 0.798 & 0.798 \\
1 & 0.764 & 0.764 & & 0.563 & 0.563 \\
0.5 & 0.457 & 0.457 & & 0.382 & 0.382 \\
0.25 & 0.244 & 0.244 & & 0.228 & 0.228 \\
\hline
\end{tabular}

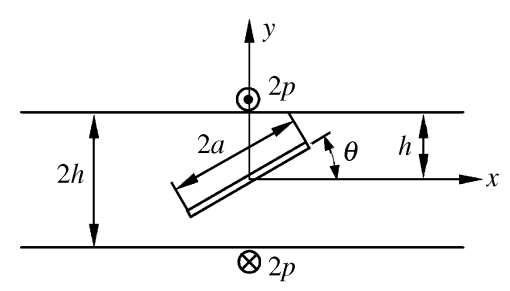

Fig. 15 An inclined crack in a strip subjected to a pair of antiplane point forces $2 p$ at boundary

to a uniformly distributed anti-plane shear stress $\tau$ applied at crack faces as shown in Fig. 16. Table 7 shows the dimensionless mode-III S.I.F. for different values of $a / h$ and $\theta$. For the case of $\theta=0^{\circ}$ and $a / h=0.5$, the present result is the same as the solution obtained by Ma (1988). For the case of $\theta=90^{\circ}$, our solution is the same as that presented by Irwin (1957).

\section{(v) An Anti-Plane Point Force Applied at Upper Boundary}

Consider an inclined crack in a strip subjected to an anti-plane point force $2 p$ applied at boundary as shown in Fig. 17. Table 8 shows the dimensionless mode-III S.I.F. for different values of $a / h$ and $\theta$. 


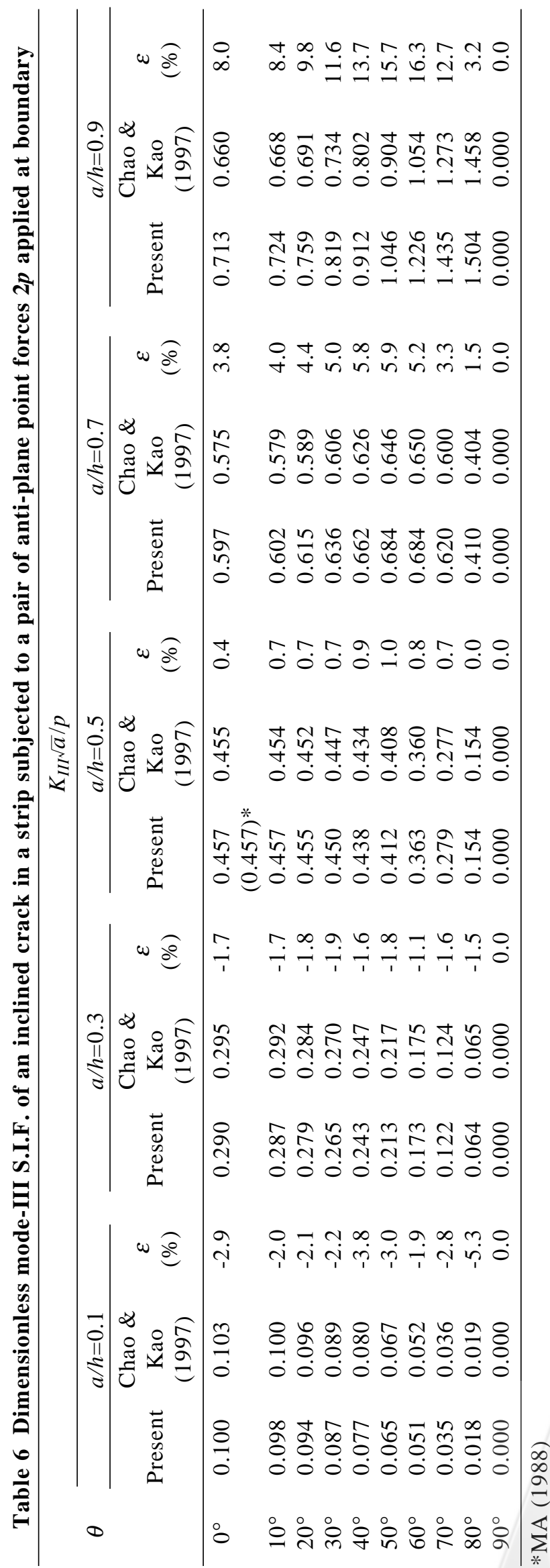


Table 7 Dimensionless mode-III S.I.F. of an inclined crack in a strip subjected to uniform anti-plane shear stress applied at crack faces

\begin{tabular}{cccccccccc}
\hline & \multicolumn{7}{c}{$K_{I I I}(\tau / \sqrt{\pi a})$} \\
\cline { 2 - 9 }$\theta$ & $a / h=0.1$ & 0.2 & 0.3 & 0.4 & 0.5 & 0.6 & 0.7 & 0.8 & 0.9 \\
\hline $0^{\circ}$ & 1.002 & 1.008 & 1.018 & 1.031 & $\begin{array}{c}1.047 \\
(1.047)^{* *}\end{array}$ & 1.064 & 1.084 & 1.105 & 1.127 \\
$10^{\circ}$ & 1.002 & 1.008 & 1.018 & 1.032 & 1.049 & 1.068 & 1.089 & 1.112 & 1.136 \\
$20^{\circ}$ & 1.002 & 1.009 & 1.020 & 1.035 & 1.054 & 1.077 & 1.103 & 1.131 & 1.163 \\
$30^{\circ}$ & 1.003 & 1.010 & 1.023 & 1.041 & 1.064 & 1.092 & 1.126 & 1.166 & 1.212 \\
$40^{\circ}$ & 1.003 & 1.012 & 1.027 & 1.048 & 1.076 & 1.113 & 1.159 & 1.216 & 1.289 \\
$50^{\circ}$ & 1.003 & 1.013 & 1.030 & 1.055 & 1.090 & 1.137 & 1.199 & 1.284 & 1.403 \\
$60^{\circ}$ & 1.003 & 1.015 & 1.034 & 1.063 & 1.104 & 1.162 & 1.245 & 1.367 & 1.565 \\
$70^{\circ}$ & 1.004 & 1.016 & 1.037 & 1.069 & 1.117 & 1.186 & 1.289 & 1.458 & 1.779 \\
$80^{\circ}$ & 1.004 & 1.017 & 1.039 & 1.074 & 1.125 & 1.202 & 1.323 & 1.534 & 2.005 \\
$90^{\circ}$ & 1.004 & 1.017 & 1.040 & 1.075 & 1.128 & 1.208 & 1.336 & 1.565 & 2.113 \\
& $(1.004)^{*}$ & $(1.017)^{*}$ & $(1.040)^{*}$ & $(1.075)^{*}$ & $(1.128)^{*}$ & $(1.208)^{*}$ & $(1.336)^{*}$ & $(1.565)^{*}$ & $(2.113)^{*}$ \\
\hline
\end{tabular}

*Irwin (1957) **MA (1988)

Table 8 Dimensionless mode-III S.I.F. of an inclined crack in a strip subjected to an anti-plane point force applied at upper boundary

\begin{tabular}{|c|c|c|c|c|c|c|c|c|c|c|}
\hline \multirow{3}{*}{$\theta$} & \multicolumn{10}{|c|}{$K_{I I I} \sqrt{a} / p$} \\
\hline & \multicolumn{2}{|c|}{$a / h=0.1$} & \multicolumn{2}{|c|}{0.3} & \multicolumn{2}{|c|}{0.5} & \multicolumn{2}{|c|}{0.7} & \multicolumn{2}{|c|}{0.9} \\
\hline & Tip A & Tip B & Tip A & Tip B & Tip A & Tip B & Tip A & Tip B & Tip A & Tip B \\
\hline $0^{\circ}$ & 0.0498 & 0.0498 & 0.1448 & 0.1448 & 0.2284 & 0.2284 & 0.2986 & 0.2986 & 0.3567 & 0.3567 \\
\hline $10^{\circ}$ & 0.0478 & 0.0504 & 0.1326 & 0.1545 & 0.2022 & 0.2544 & 0.2586 & 0.3432 & 0.3047 & 0.4197 \\
\hline $20^{\circ}$ & 0.0444 & 0.0494 & 0.1186 & 0.1604 & 0.1768 & 0.2783 & 0.2240 & 0.3912 & 0.2646 & 0.4940 \\
\hline $30^{\circ}$ & 0.0400 & 0.0468 & 0.1035 & 0.1614 & 0.1525 & 0.2977 & 0.1953 & 0.4411 & 0.2381 & 0.5811 \\
\hline $40^{\circ}$ & 0.0347 & 0.0424 & 0.0876 & 0.1557 & 0.1294 & 0.3086 & 0.1721 & 0.4899 & 0.2275 & 0.6848 \\
\hline $50^{\circ}$ & 0.0286 & 0.0364 & 0.0711 & 0.1418 & 0.1068 & 0.3052 & 0.1529 & 0.5313 & 0.2348 & 0.8111 \\
\hline $60^{\circ}$ & 0.0220 & 0.0288 & 0.0540 & 0.1186 & 0.0836 & 0.2791 & 0.1335 & 0.5510 & 0.2587 & 0.9675 \\
\hline $70^{\circ}$ & 0.0149 & 0.0200 & 0.0364 & 0.0859 & 0.0583 & 0.2205 & 0.1065 & 0.5139 & 0.2845 & 1.1507 \\
\hline $80^{\circ}$ & 0.0075 & 0.0102 & 0.0183 & 0.0453 & 0.0302 & 0.1242 & 0.0626 & 0.3473 & 0.2525 & 1.2518 \\
\hline $90^{\circ}$ & 0.0000 & 0.0000 & 0.0000 & 0.0000 & 0.0000 & 0.0000 & 0.0000 & 0.0000 & 0.0000 & 0.0000 \\
\hline
\end{tabular}

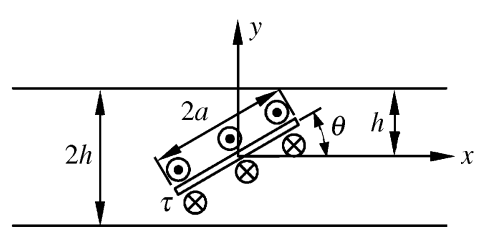

Fig. 16 An inclined crack in a strip subjected to uniform anti-plane shear stress $\tau$ at crack faces

(vi) An Inclined Crack in a Strip with Fixed Lower Boundary Subjected to an Anti-Plane Point Force Applied at Upper Boundary

Consider an inclined crack in a strip with fixed lower boundary subjected to an anti-plane point force $2 p$ applied at upper boundary as shown in Fig. 18. Table 9 shows the dimensionless mode-III S.I.F. for different values of $a / h$ and $\theta$.

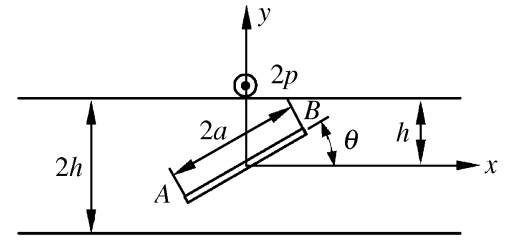

Fig. 17 An inclined crack in a strip subjected to an anti-plane point force at upper boundary

\section{An Inclined Crack in a Thin Layer Bonded to a Half Plane}

(i)An Inclined Crack in a Thin Layer Bonded to a Half Plane Subjected to an Anti-Plane Point Force $2 p$ Applied at the Boundary

Figure 19 shows an inclined crack in a thin layer bonded to a half plane subjected to an anti-plane point 
Table 9 Dimensionless mode-III S.I.F. of an inclined crack in a strip with fixed lower boundary subjected to an anti-plane point force applied at upper boundary

\begin{tabular}{|c|c|c|c|c|c|c|c|c|c|c|}
\hline \multirow{3}{*}{$\theta$} & \multicolumn{10}{|c|}{$K_{I I I^{\sqrt{a}}} / p$} \\
\hline & \multicolumn{2}{|c|}{$a / h=0.1$} & \multicolumn{2}{|c|}{0.3} & \multicolumn{2}{|c|}{0.5} & \multicolumn{2}{|c|}{0.7} & \multicolumn{2}{|c|}{0.9} \\
\hline & Tip A & Tip B & Tip A & Tip B & Tip A & Tip B & Tip A & Tip B & Tip A & Tip B \\
\hline $0^{\circ}$ & 0.0704 & 0.0704 & 0.2048 & 0.2048 & 0.3231 & 0.3231 & 0.4223 & 0.4223 & 0.5045 & 0.5045 \\
\hline $10^{\circ}$ & 0.0685 & 0.0703 & 0.1951 & 0.2101 & 0.3044 & 0.3382 & 0.3969 & 0.4471 & 0.4757 & 0.5362 \\
\hline $20^{\circ}$ & 0.0646 & 0.0681 & 0.1814 & 0.2103 & 0.2822 & 0.3493 & 0.3695 & 0.4725 & 0.4464 & 0.5745 \\
\hline $30^{\circ}$ & 0.0589 & 0.0637 & 0.1640 & 0.2044 & 0.2559 & 0.3549 & 0.3384 & 0.4988 & 0.4133 & 0.6234 \\
\hline $40^{\circ}$ & 0.0516 & 0.0571 & 0.1431 & 0.1914 & 0.2252 & 0.3523 & 0.3018 & 0.5248 & 0.3729 & 0.6879 \\
\hline $50^{\circ}$ & 0.0430 & 0.0485 & 0.1191 & 0.1701 & 0.1895 & 0.3364 & 0.2583 & 0.5461 & 0.3222 & 0.7742 \\
\hline $60^{\circ}$ & 0.0333 & 0.0381 & 0.0922 & 0.1395 & 0.1486 & 0.2995 & 0.2066 & 0.5498 & 0.2595 & 0.8898 \\
\hline $70^{\circ}$ & 0.0227 & 0.0263 & 0.0629 & 0.0997 & 0.1027 & 0.2323 & 0.1462 & 0.5037 & 0.1857 & 1.0363 \\
\hline $80^{\circ}$ & 0.0115 & 0.0134 & 0.0319 & 0.0521 & 0.0526 & 0.1295 & 0.0767 & 0.3377 & 0.1029 & 1.1342 \\
\hline $90^{\circ}$ & 0.0000 & 0.0000 & 0.0000 & 0.0000 & 0.0000 & 0.0000 & 0.0000 & 0.0000 & 0.0000 & 0.0000 \\
\hline
\end{tabular}

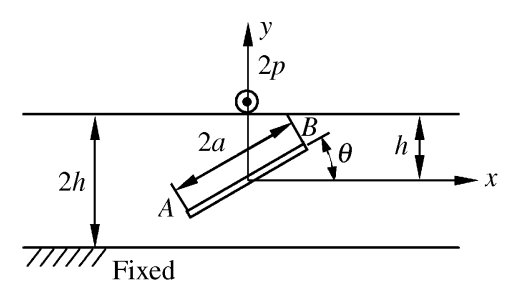

Fig. 18 An inclined crack in a strip with fixed lower boundary subjected to an anti-plane point force at upper boundary

force $2 p$ applied at the boundary. First, the critical case for $\frac{\mu_{1}}{\mu_{2}}=10000$ and $\frac{\mu_{1}}{\mu_{2}}=0.0001$ are evaluated and are checked with the solutions of a crack in a strip with free or fixed lower boundary, and the results are presented in Table 10 and Table 11. The excellent agreements prove the validity of the present method in reduced problems. Then, the case investigated by Chao and Kao (1997) is considered, the shear modulus is $\mu_{1}=194.7 \mathrm{Gpa}$ for the thin layer and $\mu_{2}=$ $229.5 \mathrm{Gpa}$ for the half plane. The results are indicated in Table 12. Obvious differences between the present result and Chao and Kao (1997) are found.

(ii) An Inclined Crack in a Thin Layer Bonded to a Half Plane Subjected to Uniform Shear Stress Applied at Crack Faces

Figure 20 shows an inclined crack in a thin layer bonded to a half plane subjected to uniform shear stress $\tau$ applied at crack faces. First, the critical case for $\frac{\mu_{1}}{\mu_{2}}=10000$ is considered and the results are verified by the solution of a crack in a strip as presented in Table 13, the distinct values are symbolized by $(*)$. The comparison shows that the solutions

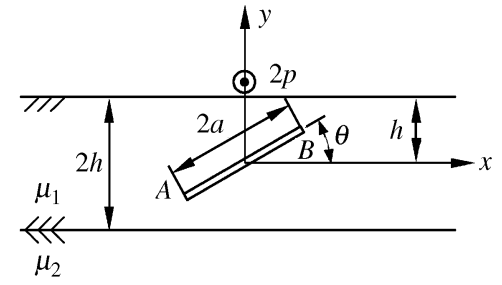

Fig. 19 An inclined crack in thin layer bonded to half plane subjected to an anti-plane point force at the boundary

of thin layer for $\frac{\mu_{1}}{\mu_{2}}=10000$ are close to the solutions for a strip. Finally, the cases of $\frac{\mu_{1}}{\mu_{2}}=2$ and $\frac{\mu_{1}}{\mu_{2}}=\frac{1}{3}$ are considered, the results are shown in Table 14 and Table 15 , respectively.

\section{CONCLUSION}

In this study, we present alternating procedures to evaluate the mode-III S.I.F. of an inclined crack embedded in a thin layer which is bonded to a half plane. The numerical results confirm the validity of the proposed alternating procedure. The solutions of a bi-material problem and a thin layer bonded to a half plane subjected to an anti-plane point force are referred to as fundamental solutions. By using these fundamental solutions and alternating procedure, the stress intensity factors of an inclined crack in a thin layer bonded to a half plane are evaluated. The numerical results of critical cases for $\frac{\mu_{1}}{\mu_{2}}=10000$ and $\frac{\mu_{1}}{\mu_{2}}=$ 0.0001 are checked with the solutions of a crack in a strip with free or fixed lower boundary and excellent agreements are obtained. The analytical alternating method proposed in this study is found to be a simple and accurate technique for the computation of modeIII S.I.F. of the cracked layer problem. 
Table 10 Comparison of the critical case for $\frac{\mu_{1}}{\mu_{2}}=10000$ and an inclined crack in a strip subjected to an anti-plane point force applied at upper boundary

\begin{tabular}{|c|c|c|c|c|c|c|}
\hline \multirow{3}{*}{$\theta$} & \multicolumn{5}{|c|}{$K_{I I I} \sqrt{a} / p(a / h=0.5)$} & \\
\hline & \multicolumn{3}{|c|}{ Tip A } & \multicolumn{3}{|c|}{ Tip B } \\
\hline & $\overline{\frac{\mu_{1}}{\mu_{2}}=10000}$ & Table 8 & $\begin{array}{c}\varepsilon \\
(\%)\end{array}$ & $\frac{\mu_{1}}{\mu_{2}}=10000$ & Table 8 & $\begin{array}{c}\varepsilon \\
(\%)\end{array}$ \\
\hline $0^{\circ}$ & 0.2284 & 0.2284 & 0.00 & 0.2284 & 0.2284 & 0.00 \\
\hline $10^{\circ}$ & 0.2022 & 0.2022 & 0.00 & 0.2543 & 0.2544 & -0.04 \\
\hline $20^{\circ}$ & 0.1768 & 0.1768 & 0.00 & 0.2782 & 0.2783 & -0.04 \\
\hline $30^{\circ}$ & 0.1525 & 0.1525 & 0.00 & 0.2976 & 0.2977 & -0.03 \\
\hline $40^{\circ}$ & 0.1294 & 0.1294 & 0.00 & 0.3085 & 0.3086 & -0.03 \\
\hline $50^{\circ}$ & 0.1068 & 0.1068 & 0.00 & 0.3051 & 0.3052 & -0.03 \\
\hline $60^{\circ}$ & 0.0835 & 0.0836 & -0.12 & 0.2790 & 0.2791 & -0.04 \\
\hline $70^{\circ}$ & 0.0583 & 0.0583 & 0.00 & 0.2205 & 0.2205 & 0.00 \\
\hline $80^{\circ}$ & 0.0302 & 0.0302 & 0.00 & 0.1242 & 0.1242 & 0.00 \\
\hline $90^{\circ}$ & 0.0000 & 0.0000 & 0.00 & 0.0000 & 0.0000 & 0.00 \\
\hline
\end{tabular}

Table 11 Comparison of the critical case for $\frac{\mu_{1}}{\mu_{2}}=0.0001$ and a crack in a strip with lower fixed boundary subjected to an anti-plane point force at upper boundary

\begin{tabular}{|c|c|c|c|c|c|c|}
\hline \multirow{3}{*}{$\theta$} & \multicolumn{6}{|c|}{$K_{I I I} \sqrt{a} / p(a / h=0.5)$} \\
\hline & \multicolumn{3}{|c|}{ Tip A } & \multicolumn{3}{|c|}{ Tip B } \\
\hline & $\overline{\mu_{1}}=0.0001$ & Table 9 & $\begin{array}{c}\varepsilon \\
(\%)\end{array}$ & $\frac{\mu_{1}}{\mu_{2}}=0.0001$ & Table 9 & $\begin{array}{c}\varepsilon \\
(\%)\end{array}$ \\
\hline $0^{\circ}$ & 0.3231 & 0.3231 & 0.00 & 0.3231 & 0.3231 & 0.00 \\
\hline $10^{\circ}$ & 0.3038 & 0.3044 & -0.20 & 0.3382 & 0.3382 & 0.00 \\
\hline $20^{\circ}$ & 0.2806 & 0.2822 & -0.57 & 0.3487 & 0.3493 & -0.17 \\
\hline $30^{\circ}$ & 0.2533 & 0.2559 & -1.02 & 0.3532 & 0.3549 & -0.48 \\
\hline $40^{\circ}$ & 0.2216 & 0.2252 & -1.60 & 0.3492 & 0.3523 & -0.88 \\
\hline $50^{\circ}$ & 0.1854 & 0.1895 & -2.16 & 0.3321 & 0.3364 & -1.28 \\
\hline $60^{\circ}$ & 0.1446 & 0.1486 & -2.69 & 0.2947 & 0.2995 & -1.60 \\
\hline $70^{\circ}$ & 0.0995 & 0.1027 & -3.12 & 0.2281 & 0.2323 & -1.81 \\
\hline $80^{\circ}$ & 0.0508 & 0.0526 & -3.42 & 0.1270 & 0.1295 & -1.93 \\
\hline $90^{\circ}$ & 0.0000 & 0.0000 & 0.00 & 0.0000 & 0.0000 & 0.00 \\
\hline
\end{tabular}

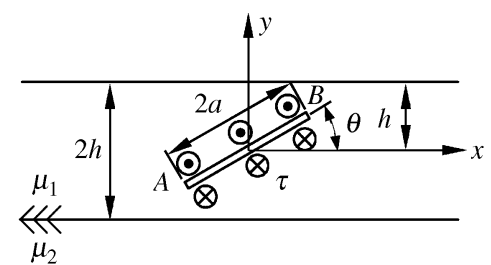

Fig. 20 An inclined crack in thin layer bonded to half plane subjected to uniform shear stress at crack face

\section{ACKNOWLEGMENTS}

The authors would like to dedicate this paper to Professor G. C. Sih for his $70^{\text {th }}$ birthday, and also for his contributions to fracture mechanics. The financial support of the authors from the National Science

Council, Republic of China, through Grant NSC912212-E-253-004 to Nanya Institute of Technology is gratefully acknowledged.

\section{NOMENCLATURE}

$f_{c}^{a}$

$g_{c}^{(j)}$

$h$

$K_{I I I A}, K_{I I I B}$ half length of the crack

residual traction on the crack faces of the $i$ 'th cycle of external alternating procedure

residual traction on the crack faces of the $j$ 'th cycle of internal alternating procedure

thickness of the strip; thickness of the layer stress intensity factor of the crack tip A 


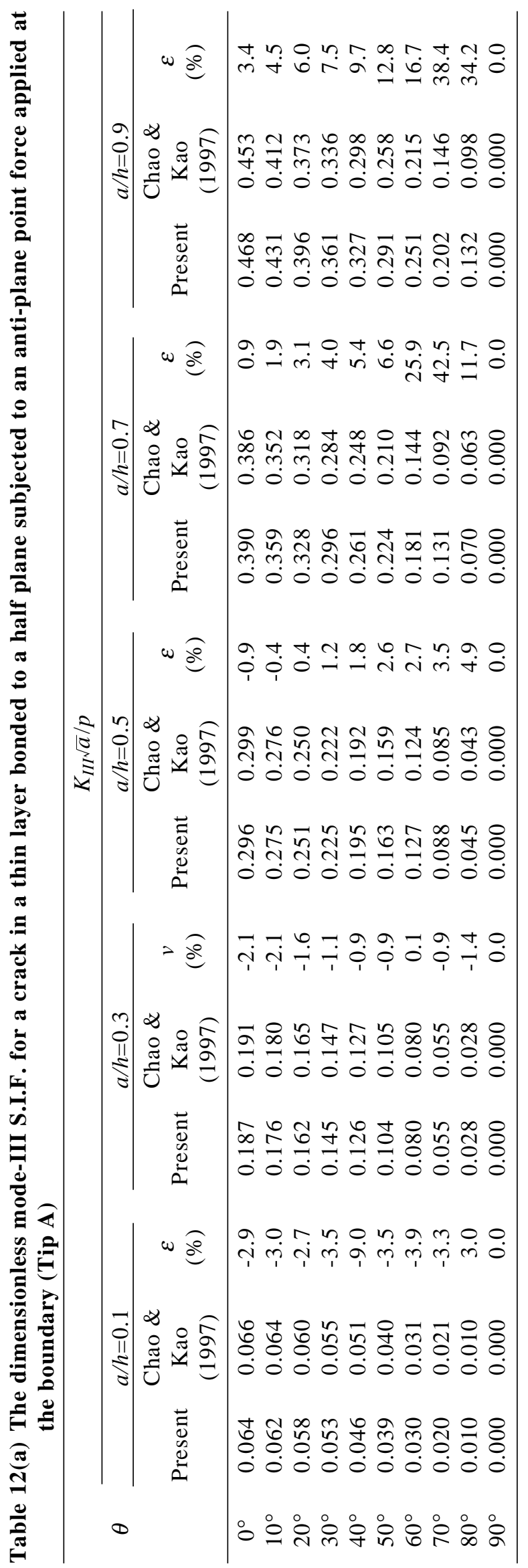

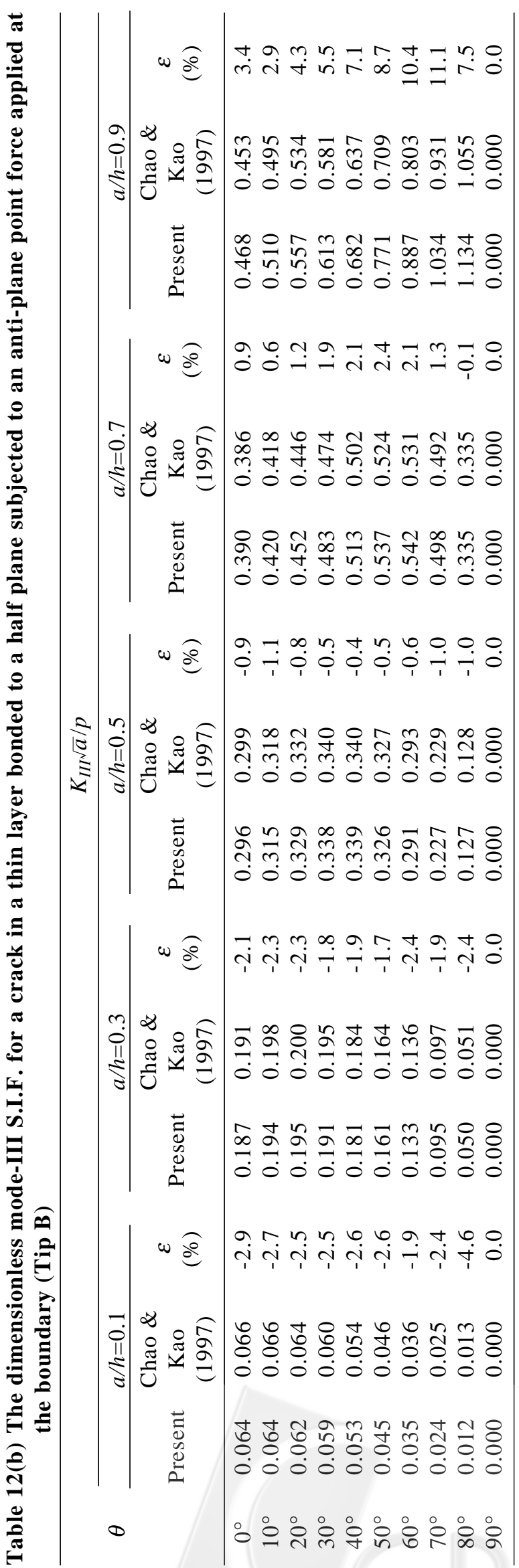


Table 13 Comparison of the critical case for a crack in a thin layer $\frac{\mu_{1}}{\mu_{2}}=10000$ and a crack in a strip subjected to uniform anti-plane shear stress applied at crack faces

\begin{tabular}{|c|c|c|c|c|c|c|c|c|c|c|}
\hline \multirow{3}{*}{$\theta$} & \multicolumn{10}{|c|}{$K_{I I I}(\tau \sqrt{\pi a})$} \\
\hline & \multicolumn{2}{|c|}{$a / h=0.1$} & \multicolumn{2}{|c|}{$a / h=0.3$} & \multicolumn{2}{|c|}{$a / h=0.5$} & \multicolumn{2}{|c|}{$a / h=0.7$} & \multicolumn{2}{|c|}{$a / h=0.9$} \\
\hline & $\begin{array}{l}\text { Thin } \\
\text { Layer }\end{array}$ & Strip & $\begin{array}{l}\text { Thin } \\
\text { Layer }\end{array}$ & Strip & $\begin{array}{l}\text { Thin } \\
\text { Layer }\end{array}$ & Strip & $\begin{array}{l}\text { Thin } \\
\text { Layer }\end{array}$ & Strip & $\begin{array}{l}\text { Thin } \\
\text { Layer }\end{array}$ & Strip \\
\hline $0^{\circ}$ & 1.002 & 1.002 & 1.018 & 1.018 & 1.047 & 1.047 & 1.084 & 1.084 & 1.127 & 1.127 \\
\hline $10^{\circ}$ & 1.002 & 1.002 & 1.018 & 1.018 & 1.049 & 1.049 & 1.089 & 1.089 & 1.136 & 1.136 \\
\hline $20^{\circ}$ & 1.002 & 1.002 & 1.020 & 1.020 & 1.054 & 1.054 & 1.103 & 1.103 & 1.163 & 1.163 \\
\hline $30^{\circ}$ & 1.003 & 1.003 & 1.023 & 1.023 & 1.064 & 1.064 & 1.126 & 1.126 & 1.212 & 1.212 \\
\hline $40^{\circ}$ & 1.003 & 1.003 & 1.026 & 1.027 & 1.076 & 1.076 & 1.158 & 1.159 & 1.289 & 1.289 \\
\hline $50^{\circ}$ & 1.003 & 1.003 & 1.030 & 1.030 & 1.090 & 1.090 & 1.199 & 1.199 & $1.402 *$ & 1.403 \\
\hline $60^{\circ}$ & 1.003 & 1.003 & 1.034 & 1.034 & 1.104 & 1.104 & 1.244 & 1.245 & $1.564 *$ & 1.565 \\
\hline $70^{\circ}$ & 1.004 & 1.004 & 1.037 & 1.037 & $1.116^{*}$ & 1.117 & 1.289 & 1.289 & $1.778 *$ & 1.779 \\
\hline $80^{\circ}$ & 1.004 & 1.004 & 1.039 & 1.039 & 1.125 & 1.125 & $1.322 *$ & 1.323 & $2.003 *$ & 2.005 \\
\hline $90^{\circ}$ & 1.004 & 1.004 & $1.039 *$ & 1.040 & 1.128 & 1.128 & $1.335^{*}$ & 1.336 & $2.111 *$ & 2.113 \\
\hline
\end{tabular}

Table 14 Dimensionless mode-III S.I.F. of an inclined crack in a thin layer $\frac{\mu_{1}}{\mu_{2}}=2$ subjected to uniform anti-plane shear stress at crack faces

\begin{tabular}{|c|c|c|c|c|c|c|c|c|c|c|}
\hline \multirow{3}{*}{$\theta$} & \multicolumn{10}{|c|}{$K_{I I I}(\tau \sqrt{\pi a})$} \\
\hline & \multicolumn{2}{|c|}{$a / h=0.1$} & \multicolumn{2}{|c|}{$a / h=0.3$} & \multicolumn{2}{|c|}{$a / h=0.5$} & \multicolumn{2}{|c|}{$a / h=0.7$} & \multicolumn{2}{|c|}{$a / h=0.9$} \\
\hline & Tip A & Tip B & Tip A & Tip B & Tip A & Tip B & Tip A & Tip B & Tip A & Tip B \\
\hline $0^{\circ}$ & 1.002 & 1.002 & 1.013 & 1.013 & 1.034 & 1.034 & 1.061 & 1.061 & 1.092 & 1.092 \\
\hline $10^{\circ}$ & 1.002 & 1.002 & 1.013 & 1.013 & 1.034 & 1.036 & 1.061 & 1.065 & 1.092 & 1.100 \\
\hline $20^{\circ}$ & 1.002 & 1.002 & 1.013 & 1.014 & 1.035 & 1.038 & 1.064 & 1.072 & 1.098 & 1.114 \\
\hline $30^{\circ}$ & 1.002 & 1.002 & 1.014 & 1.015 & 1.037 & 1.042 & 1.069 & 1.083 & 1.110 & 1.138 \\
\hline $40^{\circ}$ & 1.002 & 1.002 & 1.015 & 1.016 & 1.040 & 1.047 & 1.077 & 1.097 & 1.130 & 1.175 \\
\hline $50^{\circ}$ & 1.002 & 1.002 & 1.016 & 1.017 & 1.043 & 1.052 & 1.088 & 1.115 & 1.159 & 1.230 \\
\hline $60^{\circ}$ & 1.002 & 1.002 & 1.016 & 1.018 & 1.047 & 1.058 & 1.100 & 1.136 & 1.199 & 1.308 \\
\hline $70^{\circ}$ & 1.002 & 1.002 & 1.017 & 1.019 & 1.050 & 1.062 & 1.112 & 1.156 & 1.249 & 1.412 \\
\hline $80^{\circ}$ & 1.002 & 1.002 & 1.017 & 1.020 & 1.052 & 1.065 & 1.120 & 1.171 & 1.297 & 1.521 \\
\hline $90^{\circ}$ & 1.002 & 1.002 & 1.018 & 1.020 & 1.053 & 1.067 & 1.124 & 1.177 & 1.318 & 1.572 \\
\hline
\end{tabular}

Table 15 Dimensionless mode-III S.I.F. of an inclined crack in a thin layer $\frac{\mu_{1}}{\mu_{2}}=\frac{1}{3}$ subjected to uniform anti-plane shear stress at crack faces

\begin{tabular}{|c|c|c|c|c|c|c|c|c|c|c|}
\hline \multirow{3}{*}{$\theta$} & \multicolumn{10}{|c|}{$K_{I I I}(\tau \sqrt{\pi a})$} \\
\hline & \multicolumn{2}{|c|}{$a / h=0.1$} & \multicolumn{2}{|c|}{$a / h=0.3$} & \multicolumn{2}{|c|}{$a / h=0.5$} & \multicolumn{2}{|c|}{$a / h=0.7$} & \multicolumn{2}{|c|}{$a / h=0.9$} \\
\hline & Tip A & Tip B & Tip A & Tip B & Tip A & Tip B & Tip A & Tip B & Tip A & Tip B \\
\hline $0^{\circ}$ & 1.001 & 1.001 & 1.008 & 1.008 & 1.020 & 1.020 & 1.037 & 1.037 & 1.057 & 1.057 \\
\hline $10^{\circ}$ & 1.001 & 1.001 & 1.007 & 1.008 & 1.018 & 1.022 & 1.033 & 1.041 & 1.049 & 1.065 \\
\hline $20^{\circ}$ & 1.001 & 1.001 & 1.006 & 1.008 & 1.016 & 1.023 & 1.027 & 1.045 & 1.040 & 1.074 \\
\hline $30^{\circ}$ & 1.001 & 1.001 & 1.005 & 1.008 & 1.013 & 1.023 & 1.020 & 1.049 & 1.028 & 1.085 \\
\hline $40^{\circ}$ & 1.001 & 1.001 & 1.004 & 1.007 & 1.009 & 1.024 & 1.013 & 1.053 & 1.013 & 1.102 \\
\hline $50^{\circ}$ & 1.001 & 1.001 & 1.003 & 1.007 & 1.005 & 1.024 & 1.004 & 1.059 & 0.994 & 1.129 \\
\hline $60^{\circ}$ & 1.000 & 1.001 & 1.002 & 1.007 & 1.002 & 1.024 & 0.994 & 1.066 & 0.968 & 1.171 \\
\hline $70^{\circ}$ & 1.000 & 1.001 & 1.001 & 1.006 & 0.999 & 1.025 & 0.986 & 1.074 & 0.939 & 1.231 \\
\hline $80^{\circ}$ & 1.000 & 1.000 & 1.001 & 1.006 & 0.997 & 1.025 & 0.979 & 1.080 & 0.910 & 1.297 \\
\hline $90^{\circ}$ & 1.000 & 1.000 & 1.000 & 1.006 & 0.996 & 1.025 & 0.977 & 1.082 & 0.897 & 1.330 \\
\hline
\end{tabular}


and $\mathrm{B}$, respectively

$p \quad$ magnitude of the point force

$q \quad$ magnitude of the point displacement

$W \quad$ displacement

$x, y \quad$ Cartesian coordinates

$z \quad$ complex variable

$Z \quad$ complex stress function

$\mu_{1}, \mu_{2} \quad$ shear modulus of material 1 and 2 , respectively

$\tau \quad$ stress

$\omega \quad$ variable in the Fourier transform domain

\section{REFERENCES}

Bassani, J. L., and Erdogan, F., 1979, "Stress Intensity Factors in Bonded Half Planes Containing Inclined Cracks and Subjected to Antiplane Shear Loading," International Journal of Fracture, Vol. 15, No. 2, pp. 145-158.

Blanco, C., Martinez-Esnaola, J. M., Atkinson, C., and Bastero, J. M., 1995, "Coating Cracks in Materials with General Anisotropy," International Journal of Fracture, Vol. 71, No. 2, pp. 99-130.

Chang, C. Y., and Ma, C. C., 2001, "Transient Thermal Conduction Analysis of a Rectangular Plate with Multiple Insulated Cracks by the Alternating Method," International Journal of Heat and Mass Transfer, Vol. 44, No. 13, pp. 2423-2437.

Chang, C. Y., and Ma, C. C., 2002, "The Mixed-Mode Fracture Analysis of Multiple Embedded Cracks in a Semi-infinite Plane by an Analytical Alternating Method," Journal of Pressure Vessel Technology, ASME, Vol. 124, No. 4, pp. 446-456.

Chang, R. C., 1999, "Finite Thickness Cracked Layer Bonded to Viscoelastic Substrate Subjected to Antiplane Shear," International Journal of Solids and Structures, Vol. 36, No. 12, pp. 1781-1797.

Chao, C. K., and Kao, B., 1997, “A Thin Cracked Layer Bonded to an Elastic Half-Space under an Antiplane Concentrated Load," International Journal of Fracture, Vol. 83, No. 3, pp. 223-241.

Chen, W. H., and Chang, C. S., 1989, "Analysis of Two Dimensional Fracture Problems with Multiple Cracks under Mixed Boundary Conditions," Engineering of Fracture Mechanics, Vol. 34, No. 4, pp. 921-934.

Choi, S. Y., and Earmme, Y. Y., 1996, “An Alternating Technique for Solving Subinterface Crack Problems," International Journal of Fracture, Vol. 78, R61-R69.

Hartranft, R. J., and Sih, G. C., 1973, Method of
Analysis and Solutions of Crack Problems, G. C. Sih ed., Noordhoff, Holland.

Irwin, G. R., 1957, "Analysis of Stresses and Strains near the End of a Crack Traversing a Plate," Transactions of the ASME, Ser. E, Journal of Applied Mechanics, Vol. 24, pp. 361-364.

Krishnamurthy, T., and Raju, I. S., 1990, “A FiniteElement Alternation Method for Two-Dimensional Mixed-Mode Crack Configuration," Engineering of Fracture Mechanics, Vol. 36, No. 2, pp. 297-311.

Ma, S. W., 1988, “A Central Crack in a Rectangular Sheet Where Its Boundary is Subjected to an Arbitrary Anti-Plane Load," Engineering of Fracture Mechanics, Vol. 30, No. 4, pp. 435-443.

O'Donoghue, P. E., Nishioka, T., and Atluri, S. N., 1985, "Multiple Coplanar Embedded Elliptical Cracks in an Infinite Solid Subject to Arbitrary Crack Face Tractions," International Journal for Numerical Methods in Engineering, Vol. 21, No. 3, pp. 437-449.

Rajiyah, H., and Atluri, S. N., 1989, "Evaluation of K-Factors and Weight Functions for 2-D MixedMode Multiple Cracks by the Boundary Element Alternation Method," Engineering of Fracture Mechanics, Vol. 32, No. 6, pp. 911-922.

Raju, I. S., and Fichter, W. B., 1989, "A FiniteElement Alternating Method for Dimensional Mode-I Crack Configurations," Engineering of Fracture Mechanics, Vol. 33, No. 4, pp. 525-540.

Raju, I. S., and Krishnamurthy, T., 1992, “A Boundary Element Alternating Method for Two-Dimensional Mixed-Mode Fracture Problems," Computational Mechanics, Vol. 10, No. 2, pp. 133-150.

Shah, R. C., and Kobayashi, A. S., 1973, "Stress Intensity Factor for an Elliptical Crack Approaching the Surface of a Semi-Infinite Solid," International Journal of Fracture, Vol. 9, pp. 133-146.

Wang, X. D., and Meguid, S. A., 1996, “On the General Treatment of an Oblique Crack near a Bimaterial Interface under Antiplane Loading," International Journal of Solids and Structures, Vol. 33, No. 17, pp. 2485-2500.

Zhang, X., and Hasebe, N., 1993, "Interactions Between Rectilinear and Circumferential Cracks," Engineering of Fracture Mechanics, Vol. 46, No. 2, pp. 311-328.

Manuscript Received: May 11, 2004 and Accepted: Jul. 02, 2004 